\title{
Seroprevalencia y detección molecular de Toxoplasma gondii en donantes de un banco de sangre de Cúcuta, Colombia
}

Angélica María Ramírez¹, Yesmit Karina Ríos¹, Néstor Fabián Galvis', Elsie Entrena², Nidia Victoria Mariño르. Diana Marcela Rangel ${ }^{1}$, María Alejandra Araque ${ }^{1}$, Darlis

Mayerlis Cabarique ${ }^{1}$, Mateo Murillo ${ }^{3}$, Jorge Enrique Gómez-Marín ${ }^{3}$

${ }^{1}$ Grupo de investigación BIOGEN, Universidad de Santander, Cúcuta, Colombia

${ }^{2}$ Banco de Sangre, E.S.E. Hospital Universitario Erasmo Meoz, Cúcuta, Colombia

${ }^{3}$ Grupo de Parasitología Molecular, Centro de Investigaciones Biomédicas, Facultad de Ciencias de la Salud, Universidad del Quindío, Armenia, Colombia

Introducción. La infección por Toxoplasma gondii puede presentarse en los humanos con un amplio rango de manifestaciones que van desde el estado asintomático hasta la enfermedad grave, según el estado inmunológico del individuo. Los mecanismos de transmisión incluyen la transfusión sanguínea, pero poco se sabe sobre la frecuencia del parásito en los bancos de sangre de Colombia.

Objetivo. Determinar la prevalencia de la infección con $T$. gondii en donantes de un banco de sangre de Cúcuta mediante técnicas de diagnóstico serológico y molecular.

Materiales y métodos. Se determinaron los anticuerpos lgG e lgM contra $T$. gondii mediante un inmunoensayo en suero en 348 donantes. Se determinó la frecuencia de ADN de $T$. gondii utilizando la reacción en cadena de la polimerasa (PCR) en sangre total de donantes seropositivos y se analizaron las variables de interés con base en la información obtenida durante la selección de donantes.

Recibido: $18 / 01 / 18$

Aceptado: $19 / 02 / 19$

Publicado: 19/02/19

Citación:

Ramírez AM, Ríos YK, Galvis NF, Entrena E, Mariño NV, Rangel DM, et al. Seroprevalencia y detección molecular de Toxoplasma gondii en donantes de un banco de sangre de Cúcuta, Colombia. Biomédica. 2019;39(Supl.2):144-56.

https://doi.org/10.7705/biomedica.v39i4.4288

\section{Correspondencia:}

Angélica María Ramírez, Bacteriología y Laboratorio Clínico, Universidad de Santander, Avenida 4 N $10 \mathrm{~N}-61$, Urbanización El Bosque, Cúcuta, Colombia Teléfono: (577) 579 1008, extensión 125; (300) 2107525 ramirezanglica@gmail.com

\section{Contribución de los autores:}

Angélica María Ramírez, Yesmit Karina Ríos, Néstor Fabián Galvis, Jorge Enrique Gómez-Marín: concepto y diseño del estudio y redacción del manuscrito Elsie Entrena y Nidia Victoria Mariño: coordinación de selección, captación y toma de muestras de los donantes

Diana Marcela Rangel, María Alejandra Araque, Darlis Mayerlis Cabarique: captación de donantes y procesamiento de muestras

Mateo Murillo: reacción en cadena de la polimerasa (PCR) en tiempo real

Todos los autores participaron en el análisis de resultados, la revisión crítica y la aprobación final del manuscrito.

Financiación:

Este trabajo se llevó a cabo con apoyo financiero de la Universidad de Santander, la E.S.E. Hospital Universitario Erasmo Meoz y el Grupo de Parasitología Molecular de la Universidad del Quindío.

Conflicto de intereses:

Los autores declaran no tener conflicto de intereses alguno con relación a la publicación de este artículo.
Resultados. De los 348 donantes participantes, 134 (38,5\%) presentaron anticuerpos IgG contra T. gondii; dos $(0,6 \%)$ de ellos presentaron tanto lgG como lgM y, en dos $(1,5 \%)$, se detectó ADN del parásito en la sangre. Un análisis bivariado evidenció una asociación entre la seropositividad para $T$. gondii y tener más de 26 años de edad $(p=0,020)$.

Conclusiones. La prevalencia de la infección con $T$. gondii encontrada en los donantes de sangre sugiere una exposición significativa al agente, la cual adquiere relevancia al detectarse la parasitemia.

Palabras clave: Toxoplasma; toxoplasmosis; donantes de sangre; prevalencia; anticuerpos; Colombia.

\section{Seroprevalence and molecular detection of Toxoplasma gondii among donors in a} blood bank in Cúcuta, Colombia

Introduction: Toxoplasma gondii infection manifests differently in humans according to their immunity ranging from asymptomatic profiles to severe disease. There are multiple transmission mechanisms including blood transfusions, but little is known about the frequency of $T$. gondii infection in Colombia's blood banks.

Objective: To determine the prevalence of $T$. gondii infection in blood donors of a blood bank in the city of Cúcuta by serological and molecular diagnostic techniques.

Materials and methods: We identified IgG and lgM antibodies against $T$. gondii by immunoassay in serum from 348 donors. The frequency of $T$. gondii DNA was determined by polymerase chain reaction (PCR) in whole blood from seropositive donors and relevant variables were analyzed based on the information obtained from surveys during blood donor selection. Results: Out of the 348 enrolled donors, 134 (38.5\%) showed IgG antibodies against $T$. gondii; two of them ( $0.6 \%$ ) had both $\operatorname{lgG}$ and $\operatorname{lgM}$, and in two of them (1.5\%), parasite DNA was detected in blood samples. A bivariate analysis indicated an association between seropositivity to $T$. gondii and being over 26 years of age $(p=0.020)$.

Conclusions: The prevalence of $T$. gondii infection found in the blood donors of this study suggests a significant exposure to the infectious agent that becomes relevant when parasitemia is detected.

Keywords: Toxoplasma; toxoplasmosis; blood donors; prevalence; antibodies; Colombia.

Toxoplasma gondii es un parásito intracelular obligado que causa la toxoplasmosis, una infección asintomática y de resolución espontánea en la mayoría de los casos, pero que también puede producir complicaciones serias que resultan en gran morbimortalidad en los fetos con infección congénita y 
en individuos con compromiso inmunológico, ya sea por una infección primaria o por reactivación de infecciones crónicas latentes (1-4). Los mecanismos conocidos de transmisión del agente incluyen las vías clásicas, como la ingestión de carne cruda o mal cocida y la de agua o alimentos contaminados con el parásito, así como la transmisión transplacentaria y las vías alternas, como el trasplante de órganos y la transfusión sanguínea $(5,6)$.

Esta zoonosis de amplia distribución geográfica se considera un riesgo para la salud global (1-3). Se estima que aproximadamente el $25 \%$, de la población mundial estaría infectada con el parásito y, aunque las prevalencias varían ampliamente de región a región, las más altas se han encontrado en Latinoamérica y en los países del África tropical, hecho que se relaciona con factores climáticos como la humedad y la temperatura cálida, los cuales favorecen la supervivencia del parásito en el ambiente $(2,7)$. La gran variabilidad de la prevalencia entre las poblaciones también se asocia con factores antropogénicos, como los hábitos de alimentación, los aspectos socioeconómicos y los sistemas sanitarios (2).

Los estudios reportados a lo largo de más de 30 años revelan una gran heterogeneidad de las prevalencias de anticuerpos contra $T$. gondii en los donantes de sangre de todo el mundo, con cifras que van desde el $1 \%$ en Namibia central hasta el $75 \%$ en el noreste de Brasil (8-14). En años recientes, en algunos de estos estudios se logró detectar la parasitemia activa mediante pruebas moleculares (15-17).

Toxoplasma gondii puede sobrevivir y mantener su potencial infeccioso en sangre con citrato y en hemocomponentes a $5^{\circ} \mathrm{C}(18)$, pero se considera que el riesgo de transmisión por transfusión sanguínea es extremadamente bajo y puede ser mitigado mediante estrategias como la leucorreducción de hemocomponentes $(19,20)$. Ni la American Association of Blood Banks (AABB) ni el European Centre for Disease Prevention and Control (ECDC) clasifican el parásito como un agente que represente amenaza para la seguridad de las transfusiones (21; Indrikovs AJ. Patógenos emergentes - amenazas invisibles, VIII Congreso Colombiano y XV Congreso Iberoamericano de Bancos de Sangre y Medicina Transfusional, mayo 15 al 18 de 2014).

Sin embargo, el riesgo de la transmisión de agentes infecciosos aumenta a medida que la frecuencia de la infección se incrementa en la población, por lo que la priorización podría ser diferente en cada área geográfica (Indrikovs AJ. Patógenos emergentes - amenazas invisibles, VIII Congreso Colombiano y XV Congreso Iberoamericano de Bancos de Sangre y Medicina Transfusional, mayo 15 al 18 de 2014). Los donantes de sangre con infección asintomática, los brotes inesperados, los fenómenos sociales como las migraciones y las particularidades biológicas del agente, como las mutaciones o la virulencia de las cepas, son aspectos que pueden alterar el estado epidemiológico de una población (21; Indrikovs AJ. Patógenos emergentes - amenazas invisibles, VIII Congreso Colombiano y XV Congreso Iberoamericano de Bancos de Sangre y Medicina Transfusional, mayo 15 al 18 de 2014). Por todo esto, es de suma importancia la vigilancia de la prevalencia y de la incidencia de una infección para reevaluar constantemente el riesgo (Indrikovs AJ. Patógenos emergentes amenazas invisibles, VIII Congreso Colombiano y XV Congreso Iberoamericano de Bancos de Sangre y Medicina Transfusional, mayo 15 al 18 de 2014).

En Colombia, la toxoplasmosis es un importante problema de salud pública que requiere más estudios $(5,7,22)$. Es importante mencionar que en las investigaciones con aislamientos de $T$. gondii recolectados alrededor 
del mundo, se ha concluido que existe una divergencia geográfica en la distribución de los genotipos; la población parasitaria es de características clonales en el hemisferio norte, en tanto que en Suramérica existe un gran polimorfismo que evidencia una mayor recombinación (23). Asimismo, se ha encontrado que la mayoría de los linajes suramericanos poseen variantes alélicas que han conferido una gran virulencia a las cepas empleadas experimentalmente en ratones (24), lo que se correlaciona con la patogenia y con el tipo de reacción inmunológica de los pacientes colombianos infectados (25), quienes presentan cuadros clínicos más graves (como en el caso de la toxoplasmosis congénita) que los de Europa y Norteamérica $(22,26)$.

En cuanto a la prevalencia de la infección con $T$. gondii en donantes de sangre, en Colombia se han hecho dos estudios previos, ambos en Medellín, uno en 1968 con 184 donantes, en el cual se encontró una prevalencia del $53 \%$ (27), y otro en el 2010 con 201 donantes, en el que se encontró una prevalencia del $29 \%(28)$.

El uso de hemocomponentes leucorreducidos por filtración en Colombia depende de las necesidades clínicas de los receptores (29) y las pruebas en donantes de sangre no incluyen la tamización de $T$. gondii (30). Tampoco se inactivan los agentes patógenos en todos los bancos de sangre ni en todos los hemocomponentes. Por ello, se vio la necesidad de obtener información epidemiológica actualizada sobre la infección en esta población específica.

El objetivo del presente trabajo fue aportar nueva información sobre la prevalencia de la infección por $T$. gondii en los donantes de un banco de sangre de Cúcuta (región nororiental de Colombia), y establecer su estado de exposición.

\section{Materiales y métodos}

\section{Sitio del estudio}

El Hospital Universitario Erasmo Meoz de Cúcuta es una entidad pública que presta servicios de salud de mediana y alta complejidad en un área de influencia que comprende 40 municipios del departamento de Norte de Santander, algunos municipios de los departamentos vecinos e, incluso, de las zonas fronterizas de Venezuela. El banco de sangre de la institución ofrece el servicio de transfusiones en el hospital y suple la necesidad de hemocomponentes, no solo allí, sino en el área metropolitana de Cúcuta y en los municipios aledaños (31).

\section{Cálculo del tamaño de la muestra y método de selección}

Este estudio descriptivo transversal se llevó a cabo en donantes de sangre aceptados siguiendo el proceso estándar de selección de donantes (32).

Se tomaron como base las estadísticas de la institución y de la red local de bancos de sangre para determinar una muestra representativa de 348 participantes frente a una población de 3.600 donantes aceptados en un periodo de seis meses, con un nivel de confianza del $95 \%$ y un margen de error del $5 \%$.

Los participantes del estudio se seleccionaron aleatoriamente entre las personas que acudieron a donar al banco de sangre o que fueron captadas por fuera del banco entre abril y julio del 2016. Previamente, se les hicieron las pruebas del caso para saber si eran aptos para donar, y se les pidió diligenciar su consentimiento informado de participación voluntaria y para el manejo de las muestras clínicas. 
Se recolectaron muestras de suero y sangre total utilizando el anticoagulante ácido etilen-diamino-tetraacético (EDTA) de cada uno de los donantes participantes en tubos diferentes a los empleados rutinariamente en el banco de sangre. Se excluyeron del estudio aquellos donantes que presentaban alguna reacción adversa a la donación y aquellos que hicieron uso de la autoexclusión confidencial después de la donación.

\section{Métodos serológicos}

Para determinar los anticuerpos lgG e lgM anti- $T$. gondii de los 348 donantes, se usó la técnica ELISA (Vircel| ${ }^{\circledR}$ ) para la detección y la captura cualitativa de inmunoglobulinas en suero siguiendo las indicaciones del fabricante.

\section{Pruebas moleculares}

Se obtuvo ADN empleando los estuches comerciales UltraClean ${ }^{\circledR}$ Blood ADN Isolation ${ }^{\mathrm{TM}}$ spin y non-spin (MoBio Laboratories, Inc.), siguiendo las indicaciones del fabricante.

Una vez identificados los donantes seropositivos, se evaluó la presencia de ADN del parásito por reacción en cadena de la polimerasa (PCR) convencional y utilizando los cebadores específicos B1F-5' GAGACACAGCGTGTTATGAACAAAT 3' y B1R-5' GCACGTCTCTTG TTCTTCTTCTGTA 3' dirigidos a una secuencia blanco del gen $B 1$ (el cual tiene 35 repeticiones en el genoma del parásito), según un protocolo descrito previamente (33).

La mezcla de amplificación se hizo en un volumen final de $50 \mu \mathrm{l}$ que contenía 1X del tampón de la enzima, $1 \mu \mathrm{M}$ de cada cebador, $1 \mathrm{U}$ de Taq polimerasa (MyTaq Bioline ${ }^{\mathrm{TM}}$ ) y 2-4 $\mu \mathrm{l}$ de ADN.

El programa de amplificación incluyó una desnaturalización inicial a $94{ }^{\circ} \mathrm{C}$ durante cinco minutos, seguida de 30 ciclos con una desnaturalización a $94{ }^{\circ} \mathrm{C}$ durante un minuto, hibridación a $58{ }^{\circ} \mathrm{C}$ durante un minuto y polimerización a $72{ }^{\circ} \mathrm{C}$ durante un minuto; posteriormente, se hizo una polimerización final a $72{ }^{\circ} \mathrm{C}$ durante siete minutos.

Se utilizó un control positivo de ADN de $T$. gondii obtenido de taquizoítos de la cepa $\mathrm{RH}$ (donada por el Grupo de Investigación de Parasitología Molecular, GEPAMOL, de la Universidad del Quindío), un control negativo (agua destilada) para comprobar la inocuidad de los materiales utilizados en la mezcla de PCR y un marcador con peso molecular de $100 \mathrm{pb}$ (HyperLadder ${ }^{\mathrm{TM}}$, Bioline), con el fin de determinar el tamaño de los fragmentos amplificados según las condiciones de corrida descritas.

En los casos en que la PCR convencional reveló productos de amplificación, la detección de ADN de $T$. gondii se hizo amplificando mediante PCR en tiempo real la región repetitiva $R E$ con los siguientes cebadores: 5' GCCACAGAAGGGACAGAA GT 3' y 5' ACC CTC GCC TTC ATC TAC AG 3'y la sonda 5'6-FAM TAC AGA CGC GAT GCC GCT CC MGB NFQ 3'del estuche Platinum Quantitative PCR SuperMix-UDG ${ }^{\text {TM }}$ (11730017), y $5 \mu \mathrm{l}$ de ADN de las diferentes muestras clínicas.

Para la PCR en tiempo real, se empleó el termociclador StepOnePlus ${ }^{\mathrm{TM}}$ (Life Technologies), con el siguiente programa: a $50{ }^{\circ} \mathrm{C}$ durante dos minutos, a $95^{\circ} \mathrm{C}$ durante dos minutos y 40 ciclos a $95^{\circ} \mathrm{C}$ durante 15 segundos y a $60^{\circ} \mathrm{C}$ durante 30 segundos, según la metodología descrita previamente (33). 


\section{Recolección de la información y análisis de las variables epidemiológicas}

La información se obtuvo consultando la base de datos del banco de sangre manejada exclusivamente por su equipo de coordinación y mediante una entrevista presencial estructurada hecha a cada uno de los donantes participantes durante la flebotomía. Se obtuvieron los datos sobre las características sociodemográficas y las variables de interés, algunas con la imputación de factores de riesgo para toxoplasmosis de otras investigaciones. Las variables fueron: sexo, edad, estrato socioeconómico, ocupación, afiliación a servicios de salud, municipio de residencia, tipo de donante, antecedente de transfusión sanguínea, grupo sanguíneo, consumo de carne y grado de cocción, tipo de agua consumida y convivencia con mascotas.

La información se sistematizó inicialmente en una base de datos en Microsoft Excel 2010 y luego se procesó con el programa estadístico SPSS Statistics ${ }^{\mathrm{TM}}$, versión 21 (IBM). Se determinó la prevalencia de infección por T. gondii, se aplicó la prueba de ji al cuadrado de Pearson para establecer la asociación de la seropositividad con algunas variables de interés, tomando como significación estadística un valor de $p<0,05$, y se calcularon las razones de momios (OR) y sus correspondientes intervalos de confianza (IC) de $95 \%$.

Además, se usó una prueba de hipótesis para la diferencia de proporciones entre la prevalencia global de exposición a toxoplasmosis en donantes de sangre reportada por Forountan-Rad, et al. (8), y la prevalencia encontrada en el presente estudio.

\section{Consideraciones éticas}

Se consideraron las normas científicas, técnicas y administrativas para la investigación en salud en Colombia establecidas en la Resolución 8430 de 1993 y la Resolución 2378 del 2008 del Ministerio de Salud y Protección Social. Se les pidió a los donantes de sangre seleccionados firmar el consentimiento informado de participación voluntaria y otro para el manejo de las muestras clínicas, los cuales fueron revisados y avalados conjuntamente con la propuesta de investigación por el Comité de Ética de la Empresa Social del Estado Hospital Universitario Erasmo Meoz (Rad. 2015-136-01314-2) y el Comité de Ética e Investigaciones de la Universidad de Santander.

\section{Resultados}

\section{Prevalencia de anticuerpos anti-Toxoplasma gondii}

La detección de anticuerpos contra $T$. gondii en los 348 participantes mediante ELISA fue de 132 (37,9\%) donantes anti- $T$. gondii $\operatorname{lgG}(+) / \operatorname{lgM}(-)$ y $2(0,6 \%) \operatorname{lgG}(+) /$ $\operatorname{lgM}(+)$. No se encontraron donantes con presentación exclusiva de anticuerpos IgM. La seroprevalencia de los anticuerpos anti- $T$. gondii entre los donantes de sangre del Hospital Universitario Erasmo Meoz fue de 38,5\% (IC $\left.{ }_{95 \%}: 33,5-43,7\right)$.

\section{Frecuencia de ADN de Toxoplasma gondii en la PCR}

En la PCR convencional se detectaron productos de amplificación débiles de ADN del parásito en dos (1,5\%) de los 134 donantes seropositivos (figura 1). Dichos donantes presentaron en ambos casos un perfil de anticuerpos anti- T. gondii $\lg \mathrm{G}(+)$ e $\operatorname{lgM}(-)$. Ambas muestras se confirmaron mediante la PCR en tiempo real al obtener la amplificación de la región repetitiva $R E$ de $T$. gondii (figura 2 ). 


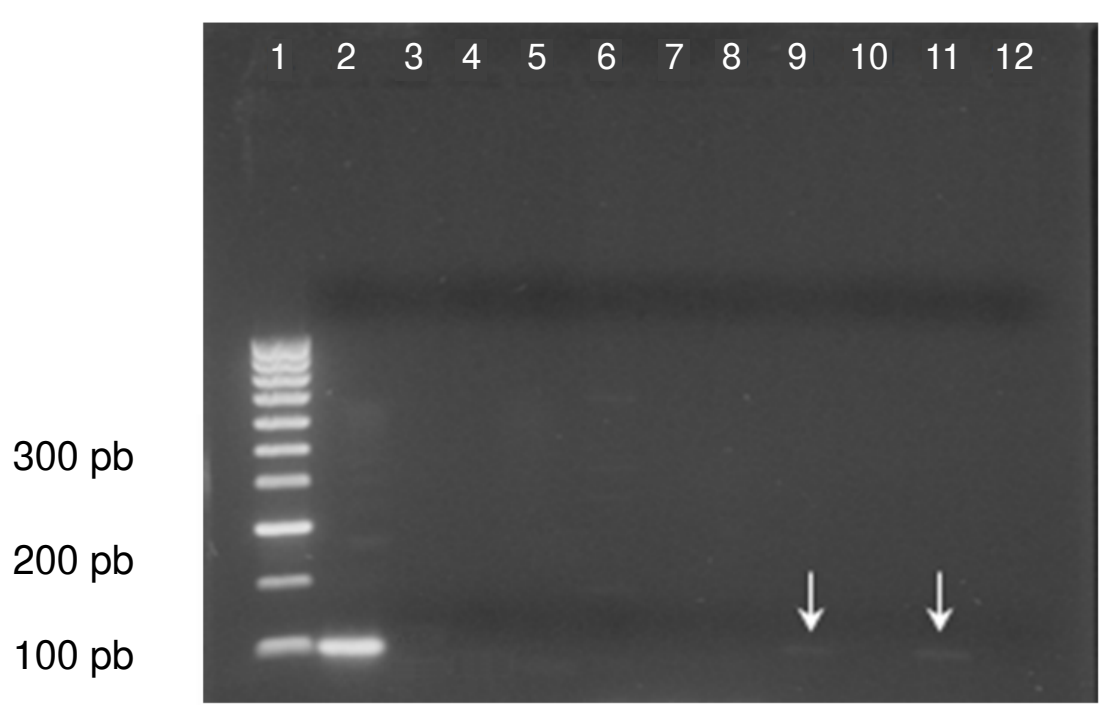

Figura 1. Electroforesis en gel de agarosa al 1,2\% con los resultados de la PCR convencional para la detección de $T$. gondii en muestras de donantes de sangre. En el pozo 1: marcador de peso molecular de 100 pb (HyperLadder ${ }^{\mathrm{TM}}$ ); en el pozo 2: control positivo (ADN T. gondii cepa $\mathrm{RH}$ ); en los pozos 3 a 10: muestras de donantes de sangre (nótense en los pozos 9 y 11, productos de amplificación débiles); en el pozo 12: control negativo (agua destilada)

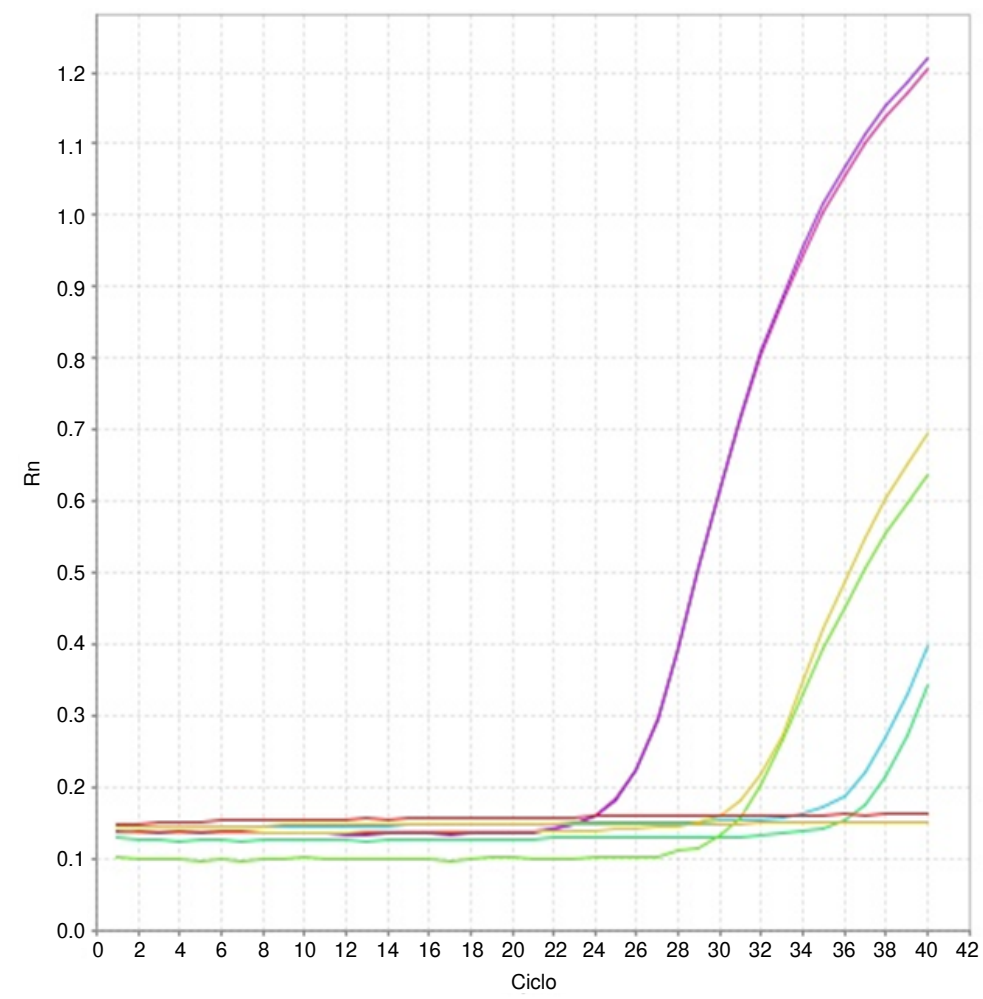

Figura 2. Gráfica de amplificación de la región repetitiva RE de T. gondii por PCR en tiempo real. Control positivo (ADN de la cepa RH de $T$. gondii). Control threshold (CT), 24,89 (color morado); donante de sangre del Hospital Universitario Erasmo Meoz seropositivo con parasitemia detectada por PCR convencional (pozo 9): CT 30,87 (colores verde y naranja); donante de sangre del Hospital Universitario Erasmo Meoz seropositivo con parasitemia detectada mediante PCR convencional (pozo 11): CT 36,63 (color azul). 


\section{Variables sociodemográficas y de interés epidemiológico}

Se encontró que $247(71,0 \%)$ de los donantes participantes eran hombres y la edad promedio fue de 28 años. El rango de edad aceptado para donar sangre en Colombia es de 18 a 65 años (33) y, en el estudio, el rango de edad fue de 18 a 56 años; 196 (56,3\%) donantes tenían 26 años o menos, es decir, el grupo etario considerado como población joven según la clasificación de ciclos vitales empleada por el Ministerio de Salud y Protección Social de Colombia en sus análisis epidemiológicos y demográficos (34). Se encontró una asociación significativa entre tener más de 26 años y la seropositividad para T. gondii $(p<0,02)$ (cuadro 1).

En cuanto al nivel socioeconómico, el 41,4 \% de los donantes pertenecía a los estratos 1 (9/348) y 2 (135/348) según la clasificación del Departamento Administrativo Nacional de Estadística de Colombia (DANE) (35), en tanto que el resto del grupo residía en zonas de estrato 3 (177/348), 4 (26/348) y 5 (1/348); no hubo participantes de estrato socioeconómico 6.

Cuadro 1. Variables de interés y detección serológica de anticuerpos anti- $T$. gondii en donantes del banco de sangre del Hospital Universitario Erazmo Meoz, Cúcuta, Colombia

\begin{tabular}{|c|c|c|c|c|c|c|}
\hline \multirow[t]{2}{*}{ Variables } & \multicolumn{2}{|c|}{ Donantes estudiados } & \multicolumn{2}{|c|}{$\begin{array}{c}\text { Donantes seropositivos } \\
\text { para } T \text {. gondii }\end{array}$} & \multirow{2}{*}{ OR $\left(\right.$ IC $\left._{95 \%}\right)$} & \multirow[t]{2}{*}{$\mathbf{p}$} \\
\hline & $\mathbf{n}$ & $\%$ & $\mathbf{n}$ & $\%$ & & \\
\hline \multicolumn{7}{|l|}{ Sexo } \\
\hline Femenino & 101 & 29,0 & 44 & 32,8 & 1,345 & 0,215 \\
\hline Masculino & 247 & 71,0 & 90 & 67,2 & $(0,837-2,157)$ & \\
\hline \multicolumn{7}{|l|}{ Edad (años) } \\
\hline$>26$ & 152 & 43,7 & 69 & 51,5 & 1,673 & $0,02^{*}$ \\
\hline$\leq 26$ & 196 & 56,3 & 65 & 48,5 & $(1,081-2,595)$ & \\
\hline \multicolumn{7}{|l|}{ Estrato socioeconómico } \\
\hline Bajo & 144 & 41,4 & 58 & 43,3 & 1,135 & 0,568 \\
\hline Medio/alto & 204 & 58,6 & 76 & 56,7 & $(0,731-1,761)$ & \\
\hline \multicolumn{7}{|l|}{ Ocupación } \\
\hline Ninguna/oficios varios & 55 & 15,8 & 27 & 20,2 & 0,537 & 0,078 \\
\hline $\begin{array}{l}\text { Estudiantes universitarios/ } \\
\text { técnicos/profesionales/otros }\end{array}$ & 293 & 84,2 & 107 & 79,8 & $(0,333-1,073$ & \\
\hline \multicolumn{7}{|l|}{ Afiliación a servicios de salud } \\
\hline No & 23 & 6,6 & 5 & 3,7 & 0,423 & 0,087 \\
\hline Sí & 325 & 93,4 & 129 & 96,3 & $(0,137-1,124)$ & \\
\hline \multicolumn{7}{|l|}{ Municipio de residencia } \\
\hline Cúcuta/área metropolitana & 316 & 90,8 & 121 & 90,3 & 0,478 & 0,084 \\
\hline Pamplona & 32 & 9,2 & 13 & 9,7 & $(0,197-1,135)$ & \\
\hline \multicolumn{7}{|l|}{ Consumo de carne } \\
\hline Consumo con poca cocción & 60 & 17,2 & 24 & 17,9 & 1,079 & 0,794 \\
\hline Consumo con buena cocción & 288 & 82,8 & 110 & 82,1 & $(0,604-1,903)$ & \\
\hline \multicolumn{7}{|l|}{ Tipo de agua consumida } \\
\hline Acueducto (llave) & 122 & 35,1 & 47 & 35,1 & 0,99 & 0,996 \\
\hline $\begin{array}{l}\text { Tratamiento adicional } \\
\text { (hervida/botellón/filtro de } \\
\text { ozono) }\end{array}$ & 226 & 64,9 & 87 & 64,9 & $(0,635-1,576)$ & \\
\hline \multicolumn{7}{|l|}{ Convivencia con mascotas } \\
\hline Sí & 240 & 69,0 & 91 & 67,9 & 0,923 & 0,736 \\
\hline No & 108 & 31,0 & 43 & 32,1 & $(0,579-1,47$ & \\
\hline
\end{tabular}


Con relación a las ocupaciones, estas se organizaron en diversas categorías, siendo la de estudiantes universitarios la más frecuente. En esta variable, el factor común fue que ninguna de las ocupaciones referidas implicaba una exposición directa o constante a la tierra o a los animales.

Del total de donantes, 325 (93,4\%) estaban afiliados al Sistema de Seguridad Social en Salud en alguna de sus modalidades.

En cuanto al lugar de residencia, todos los donantes provenían de áreas urbanas, ya que el banco de sangre del Hospital Universitario Erasmo Meoz también se abastece con donaciones de Pamplona, municipio aledaño cuyas condiciones climáticas promedio $\left(2.200 \mathrm{~m} \mathrm{snm}, 16^{\circ} \mathrm{C}, 921 \mathrm{~mm}\right.$ de precipitación) son diferentes a las del área metropolitana $\left(320 \mathrm{msnm}, 28^{\circ} \mathrm{C}, 622 \mathrm{~mm}\right.$ de precipitación). Sin embargo, no se encontraron diferencias estadísticamente significativas en la seropositividad entre los donantes de las dos ciudades.

De los 348 participantes, $302(86,8 \%)$ donaron sangre voluntariamente, mientras que $46(13,2 \%)$ lo hicieron por reposición. Con respecto a la frecuencia de donación, $70(23,2 \%)$ de los donantes voluntarios eran donantes habituales o repetitivos, 61 (20,2\%), donantes no habituales, y 171 $(56,6 \%)$ donaban sangre por primera vez.

En cuanto a la seropositividad para $T$. gondii, de los 134 donantes seropositivos, $71(53,0 \%)$ eran donantes voluntarios de primera vez, 25 (18,7\%), donantes voluntarios no habituales, 31 (23,1\%), donantes voluntarios habituales, y 7 (5,2\%), donantes por reposición. Se consideran como donantes voluntarios habituales aquellos que donan sangre de manera altruista, por lo menos, dos veces en 12 meses (32).

En cuanto a otras variables que indagaban sobre la exposición al parásito, se encontró que, de los 348 donantes, 288 (82,8\%) consumían carne con buen grado de cocción, todos los donantes tenían acceso a agua potable y 226 $(64,9 \%)$ empleaban filtros de ozono para el agua o la hervían, en tanto que 240 $(69,0 \%)$ convivían con alguna mascota, el 36,7 \% (88/240) de ellos con gatos. Ninguna de estas variables tuvo una asociación significativa con la frecuencia de anticuerpos IgG anti- $T$. gondii en los donantes de sangre de este estudio.

Otras características observadas en los donantes analizados incluyeron el hecho de que ninguno presentaba antecedentes de transfusión sanguínea, 326 (93,7 \%) de ellos eran Rh positivo, y la distribución por grupo sanguíneo fue: del grupo O, 61,2\%, del A, 29,3\%, del B, 7,5\%, y del AB, 2,0 \%.

\section{Discusión}

La prevalencia de infección por T. gondii en el presente estudio fue 38,5\% $\left(\mathrm{IC}_{95 \%} 28-39\right)$, mayor que la prevalencia promedio global en donantes de sangre, que es de $33 \%$ según lo reportado por Forountan-Rad, et al., en el 2016 en el metaanálisis de 43 publicaciones de 22 países aparecidas entre enero de 1980 y junio de 2015 (8).

En cuanto a los dos estudios hechos en Colombia, se observó una mayor prevalencia que la hallada en el 2011 por Betancur, et al., (29,9\%) en 201 donantes de un banco de sangre de Medellín (28), pero menor que el $53 \%$ del estudio también llevado a cabo en Medellín en 1973 (27).

Aunque las prevalencias poblacionales del 30 al $50 \%$ de infección por T. gondii se consideran moderadas (2), debe tenerse en cuenta que este 
grado de exposición al parásito en los donantes de sangre (asumidos como población saludable), adquiere mayor relevancia cuando se detecta parasitemia mediante técnicas moleculares, como la que se encontró en dos casos del presente estudio. Es posible detectar ADN del parásito en la sangre de pacientes con infección crónica e inmunocompetentes sin que haya síntomas o contaminación en la prueba de PCR $(24,36)$.

Dado que la PCR no permite determinar si el parásito es viable, podría pensarse que se presentan reactivaciones locales del parásito que son controladas por el sistema inmunológico, aunque no se puede descartar que exista un potencial infeccioso. Se necesitarían más estudios para determinar la viabilidad de los parásitos que circulan en sangre, lo cual podría hacerse mediante PCR con transcriptasa inversa (RT-PCR) para detectar el ARN del parásito o mediante cultivo de la sangre en ratón.

En un estudio de toxoplasmosis ocular en Brasil, se detectó Toxoplasma spp. por inmunofluorescencia y positividad en muestras de sangre en la PCR, pero no se realizaron cultivos en ratón para poder evaluar si los parásitos eran viables (37), lo cual es importante para establecer, por ejemplo, si una PCR positiva en sangre sería un indicador de riesgo en las donaciones de sangre.

Al igual que lo reportado en muchos estudios del agente, en este se evidenció una asociación entre la edad y la seropositividad para T. gondii, lo que se explicaría por la mayor probabilidad de haber estado expuesto al parásito a medida que aumenta la edad, es decir, se espera que, a mayor edad, la prevalencia de la infección también aumente $(8,12,14,38)$.

Entre las limitaciones del estudio debe mencionarse que no se pudieron cubrir algunos factores externos, como el fenómeno de El Niño, que en el 2016 se catalogó como uno de los más fuertes en la historia del país y que afectó la región con un incremento de $2,2^{\circ} \mathrm{C}$ en la temperatura de la ciudad y un déficit acumulado de lluvias del $53 \%$ en el departamento (39), hecho que habría aumentado la desecación del suelo, afectando la viabilidad del parásito, asociada, como se sabe, con el nivel de pluviosidad (7).

En cuanto al tipo de donantes y la presentación de anticuerpos anti- $T$. gondii, se observó que la mayoría de los donantes seropositivos en este estudio fueron voluntarios de primera vez y debe tenerse en cuenta el bajo porcentaje de donantes por reposición que participaron.

Si bien el sistema de reposición todavía se acepta y es necesario para el abastecimiento de los bancos de sangre en Colombia y en muchos otros países sin una cultura bien arraigada de donación voluntaria, altruista y repetitiva, este tipo de donación puede resultar coercitiva y encubrir situaciones que aumentan el riesgo de infecciones transmitidas por transfusión, por lo que su eliminación constituye una meta claramente establecida por la Organización Mundial de la Salud (OMS) en el marco de los planes regionales para el acceso universal a sangre segura (40). Por otro lado, hay estudios en los que se ha visto que la reacción a los marcadores de infección también se asocia con la donación voluntaria de primera vez, incluso más que a la de reposición en algunos casos (41).

Para explorar más la relación de la seropositividad con el tipo y la frecuencia de la donación, se requeriría ampliar el estudio con un muestreo representativo para cada tipo de donación. Lo mismo se recomienda con otros factores de riesgo de exposición a $T$. gondii que no pudieron cubrirse o analizarse más a fondo en 
el presente estudio, como el tipo de mascotas, el contacto con gatos en casa y en sus alrededores, el tipo de vivienda, así como el tipo de sangre y los antecedentes de transfusión sanguínea incluidas en otros estudios recientes $(42,43)$.

Además, cabe mencionar que la heterogeneidad de prevalencias observada en los estudios en donantes de sangre (8) puede deberse a las diferentes técnicas de detección de anticuerpos y al tipo de muestra empleada en los análisis. En el caso de los estudios con técnicas moleculares, como la capa leucoplaquetaria (buffy-coat) o en sangre total, podría deberse al tipo de PCR, o a la secuencia blanco del parásito por detectar $(44,45)$, o a si la detección molecular se usa en la totalidad de donantes $(15,17)$, solo en donantes seropositivos o solo en donantes con lgM específica positiva (16).

Con respecto al hallazgo de anticuerpos IgM y la detección de ADN del parásito en la sangre de los donantes, debe resaltarse que esto no indica estrictamente la viabilidad del agente o la capacidad infecciosa de la sangre donada $(44,45)$. En T. gondii, la IgM es detectable desde las dos primeras semanas de primoinfección y puede perdurar entre seis y 18 meses e, incluso, hasta dos años en promedio, según lo observado en modelos matemáticos aplicados en Colombia. Existen lgM naturales que pueden reconocer Toxoplasma sin que se haya presentado una infección (1).

Por otro lado, aunque no es frecuente, la detección de ADN de T. gondii en sangre de individuos con infección crónica (IgG positivos e lgM negativos) demuestra que la detección de la parasitemia no es exclusiva de los individuos con infecciones agudas, tal como ya se explicó. En algunos estudios en individuos asintomáticos crónicos, se ha detectado parasitemia mediante técnicas moleculares, y algunos hallazgos sugieren que el parásito podría haberse liberado de los quistes en músculos y en el tejido nervioso en infecciones pasadas $(36,46)$.

Se ha concluido que el parásito puede circular en la sangre de individuos inmunocompetentes a partir de la reactivación, haya enfermedad ocular o no (46), como podría ocurrir en los donantes de sangre, y la ausencia de síntomas indicaría que el sistema inmunitario logró controlar adecuadamente esas reactivaciones. Esto justificaría, entonces, la necesidad de hacer el análisis molecular, no solo en los casos con IgM positiva, sino en todos los donantes con lgG específica positiva, ya que la serología, por sí sola, no sería un método efectivo como prueba de tamización. Para definir esto, se deben hacer estudios que determinen la viabilidad del parásito y el potencial infeccioso de las donaciones.

Dada la naturaleza intracelular de $T$. gondii, se considera que la leucorreducción por filtración y la transfusión con hemocomponentes provenientes de donantes seronegativos en receptores vulnerables, son estrategias adecuadas de mitigación del riesgo del parásito para la seguridad de las transfusiones que hacen innecesarias las pruebas de tamización en los donantes $(19,20)$. Sin embargo, debe tenerse en cuenta que, para algunos expertos, la adopción de la leucorreducción universal es controversial pues, a pesar de sus ventajas, en algunos países donde ya se han evaluado sus costos y beneficios, no se ha evidenciado plenamente su eficiencia (47).

La implementación de algoritmos adecuados y el abastecimiento suficiente de los bancos de sangre en regiones con alta prevalencia de infección por $T$. gondii, representan un gran reto a la hora de tomar decisiones acertadas y rechazar aquellas soluciones que resultan poco costo efectivas sin descuidar el bienestar de la población. 
En conclusión, la seroprevalencia para anticuerpos anti- $T$. gondii de $38,5 \%$ hallada en este estudio en 348 donantes de sangre del Hospital Universitario Erasmo Meoz, sugiere una exposición significativa al agente, que adquiere relevancia al haberse detectado el ADN del parásito en la sangre en dos de los participantes. Dada su versatilidad y complejidad biológica, este agente no debe subestimarse, por lo que se recomienda hacer nuevos estudios sobre su impacto en las donaciones de sangre.

\section{Agradecimientos}

A la Universidad de Santander y a la E.S.E Hospital Universitario Erasmo Meoz, por el respaldo institucional en todo sentido y, de manera muy especial, a todo el personal del Banco de Sangre, al Grupo de Investigación GEPAMOL de la Universidad del Quindío por apadrinar este proyecto, y a María Pirón de la Fundació Salut i Envelliment de la Universidad Autónoma de Barcelona, por su acompañamiento desde el inicio de la propuesta.

\section{Referencias}

1. Gómez-Marín JE. Toxoplasmosis. En: Gómez Marín JE, editor. Protozoología médica: protozoos parásitos en el contexto latinoamericano. Primera edición. Bogotá: Editorial Manual Moderno; 2010. p. 65-85.

2. Robert-Gangneux F, Dardé ML. Epidemiology of and diagnostic strategies for toxoplasmosis. Clin Microbiol Rev. 2012;25:264-96. https://doi.org/10.1128/CMR.05013-11

3. Dard C, Fricker-Hidalgo H, Brenier-Pinchart M, Pelloux H. Relevance of and new developments in serology for toxoplasmosis. Trends Parasitol. 2016;32:492-506. https://doi.org/10.1016/j.pt.2016.04.001

4. Díaz AD, Aristizábal BH. Métodos tradicionales y moleculares en el diagnóstico de la toxoplasmosis y su aplicación en el contexto clínico. Medicina UPB. 2013;32:54-67.

5. Pérez JE, Villada JS, Naranjo OD, Castaño SV. Formas alternas de transmisión de Toxoplasma gondii. Biosalud. 2011;10:123-37.

6. Siegel SE, Lunde MN, Levine AS, Graw RJ, Miller RW. Transmission of toxoplasmosis by leukocyte (WBC) transfusion. Pediatr Res. 1970;4:461. https://doi.org/10.1203/00006450-197009000-00107

7. Gómez-Marín JE, de la Torre A, Ángel-Muller E, Rubio J, Arenas J, Osorio E, et al. First Colombian multicentric newborn screening for congenital toxoplasmosis. PLoS Negl Trop Dis. 2011;5:e1195. https://doi.org/10.1371/journal.pntd.0001195

8. Foroutan-Rad M, Majidiani H, Dalvand S, Daryani A, Kooti W, Saki J, et al. Toxoplasmosis in blood donors: A systematic review and meta-analysis. Transfus Med Rev. 2016;30:116-22. https://doi.org/10.1016/j.tmrv.2016.03.002

9. van der Colf BE, Noden BH, Wilkinson R, Chipare I. Low seroprevalence of antibodies to Toxoplasma gondii in blood donors in central Namibia. S Afr J Infect Dis. 2014;29:101-4. https://doi.org/10.1080/23120053.2014.11441579

10. Coêlho RA, Kobayashi M, Carvalho Jr. LB. Prevalence of IgG antibodies specific to Toxoplasma gondii among blood donors in Recife, Northeast Brazil. Rev Inst Med Trop Sao Paulo. 2003;45:229-31. https://doi.org/10.1590/S0036-46652003000400011

11. Elhence P, Agarwal P, Prasad KN, Chaudhary RK. Seroprevalence of Toxoplasma gondii antibodies in North Indian blood donors: Implications for transfusion transmissible toxoplasmosis. Transfus Apher Sci. 2010;43:37-40. https://doi.org/10.1016/j.transci.2010.05.004

12. Alvarado-Esquivel C, Mercado-Suárez MF, Rodríguez-Briones A, Fallad-Torres L, AyalaAyala JO, Nevarez-Piedra LJ, et al. Seroepidemiology of infection with Toxoplasma gondii in healthy blood donors of Durango, México. BMC Infect Dis. 2007;7:75. https://doi.org/10.1186/1471-2334-7-75

13. Pinlaor S, Leamviteevanich K, Pinlaor P, Maleewong W, Pipitgool V. Seroprevalence of specific total immunoglobulin (lg), IgG and IgM antibodies to Toxoplasma gondii in blood donors from Loei Province, Northeast Thailand. S Afr J Infect Dis. 2000;31:123-7. 
14. Jafari Modrek M, Mousavi M, Saravani R. Toxoplasma gondii seroprevalence among blood donors in Zahedan, Southeastern Iran. Int J Infect. 2014;1:e21111 https://doi.org/10.17795/iji-21111

15. Zainodini N, Zare-Bidaki M, Abdollahi SH, Afrooz M, Ziaali N, Ebrahimian M, et al. Molecular and serological detection of acute and latent toxoplasmosis using real-time PCR and ELISA techniques in blood donors of Rafsanjan City, Iran, 2013. Iran J Parasitol. 2014;9:336-41.

16. Sarkari B, Shafiei R, Zare M, Sohrabpour S, Kasraian L. Seroprevalence and molecular diagnosis of Toxoplasma gondii infection among blood donors in southern Iran. J Infect Dev Ctries. 2014;8:543-47. https://doi.org/10.3855/jidc.3831

17. Chiang TY, Hsieh HH, Kuo MC, Chiu KT, Lin WC, Fan CK, et al. Seroepidemiology of Toxoplasma gondii Infection among healthy blood donors in Taiwan. PLoS One. 2012;7:e48139. https://doi.org/10.1371/journal.pone.0048139

18. Vasina S, Dunaeva Z. On the length of survival of Toxoplasma outside the host organism. Med Prom SSSR.1960;29:451-4.

19. Singh G, Sehgal R. Transfusion-transmitted parasitic infections. Asian J Transf Sci. 2010;4:73-7. https://doi.org/10.4103/0973-6247.67018

20. Shulman I. Parasitic infections and their impact on blood donor selection and testing. Arch Pathol Lab Med. 1994;118:366-70.

21. Stramer S, Hollinger F, Katz L, Kleinman S, Metzel P, Gregory K, et al. Emerging infectious disease agents and their potential threat to transfusion safety. Transfusion. 2009;49:1S-29S. https://doi.org/10.1111//.1537-2995.2009.02279.x

22. Cañón-Franco WA, López-Orozco N, Gómez-Marín JE, Dubey JP. An overview of seventy years of research (1944-2014) on toxoplasmosis in Colombia, South America. Parasit Vectors. 2014;7:427. https://doi.org/10.1186/1756-3305-7-427

23. Su C, Khan A, Zhou P, Majumdar D, Ajzenberg D, Dardé ML, et al. Globally diverse Toxoplasma gondii isolates comprise six major clades originating from a small number of distinct ancestral lineages. Proc Natl Acad Sci USA. 2012;109:5844-9. https://doi.org/10.1073/pnas.1203190109

24. Sánchez V, de la Torre A, Gómez-Marín JE. Characterization of ROP18 alleles in human toxoplasmosis. Parasitol Int. 2014;63:463-9. https://doi.org/10.1016/j.parint.2013.10.012

25. Torres-Morales E, Taborda L, Cardona N, de la Torre A, Sepúlveda-Arias JC, Patarroyo MA, et al. Th1 and Th2 immune response to $\mathrm{P} 30$ and ROP18 peptides in human toxoplasmosis. Med Microbiol Immunol. 2014;203:315-22. https://doi.org/10.1007/s00430-014-0339-0

26. Pernas L, Ramírez R, Holmes TH, Montoya JG, Boothroyd JC. Immune profiling of pregnant Toxoplasma-infected US and Colombia patients reveals surprising impacts of infection on peripheral blood cytokines. J Infect Dis. 2014;210:923-31. https://doi.org/10.1093/infdis/jiu189

27. Jewell M, Thompson D, Frenkel J. Toxoplasmosis: títulos de anticuerpos en humanos y gatos domésticos de Medellín, Colombia. Antioquia Med. 1973;23:145-52.

28. Betancur CA, Jaramillo JM, Puyana JD, Quintero MI, Estrada S, Salazar LM. Seroprevalencia de toxoplasmosis en donantes de sangre de la Clínica Cardiovascular Santa María, Medellín, Colombia, 2009-2010. Infectio. 2011;15:14-9.

29. Coordinación Red Nacional de Bancos de Sangre y Servicios de Transfusión, Instituto Nacional de Salud. Leucorreducción de componentes sanguíneos. Documento técnico. Fecha de consulta: 20 de diciembre de 2017. Disponible en: https://www.ins.gov.co/Direcciones/ RedesSaludPublica/DonacionSangre/Publicaciones/Manual\%20Leucoreduccion.pdf

30. Coordinación Red Nacional de Bancos de Sangre y Servicios de Transfusión, Instituto Nacional de Salud. Anexo Técnico Circular No.1-Circular No.0082 de 2011. Fecha de consulta: 21 de julio de 2017. Disponible en: https://www.ins.gov.co/Direcciones/ RedesSaludPublica/DonacionSangre/NormatividadRelNalBancosSangro/Anexo\%20 Tecnico\%203\%20Circular\%200082\%20de\%202011.pdf

31. E.S.E. Hospital Universitario Erasmo Meoz. herasmomeoz.gov.co. Fecha de consulta: 29 de septiembre de 2017. Disponible en: http://www.herasmomeoz.gov.co/index.php

32. Osorio A, Melo A, Herrera A, Patiño A, Niño B, Reina B, et al. Guía para la selección y atención de donantes de sangre y hemocomponentes en Colombia. Bogotá: Instituto Nacional de Salud; 2012. Fecha de consulta: 21 de julio de 2017. Disponible en: https://www.ins.gov.co/ Direcciones/RedesSaludPublica/DonacionSangre/Publicaciones/Gu\%C3\%ADa\%20para\%20 Selecci\%C3\%B3n\%20de\%20Donantes\%20de\%20Sangre\%20en\%20Colombia\%202013.pdf 
33. Cardona N, Basto N, Parra B, Zea AF, Pardo CA, Bonelo A, et al. Detection of Toxoplasma DNA in the peripheral blood of HIV-positive patients with neuro-opportunistic infections by a real-time PCR assay. J Neuroparasitology. 2011; 2:1-6. https://doi.org/10.4303/jnp/N110402

34. Ministerio de Salud y Protección Social. Análisis de situación de salud de poblaciones diferenciales relevantes. Colombia. Fecha de consulta: 13 de julio de 2016. Disponible en: https://www.minsalud.gov.co/sites/rid/Lists/BibliotecaDigital/RIDE/VS/ED/PSP/IMP+MS ASIS_PoblDiferenciales.pdf

35. Departamento Administrativo Nacional de Estadística. Estratificación socioeconómica. Fecha de consulta: 15 de octubre de 2017. Disponible en: http://www.dane.gov. co/index.php/servicios-al-ciudadano/servicios-de-informacion/estratificacionsocioeconomica\#preguntas-frecuentes

36. Gómez-Marín JE, de la Torre A, Barrios P, Cardona N, Álvarez C, Herrera C. Toxoplasmosis in military personnel involved in jungle operations. Acta Trop. 2012;122:46-51. https://doi.org/10.1016/j.actatropica.2011.11.019

37. Vallochi A, Goldberg A, Falcai A, Ramasawmy R, Kalil J, Silveira C, et al. Molecular markers of susceptibility to ocular toxoplasmosis, host and guest behaving badly. Clin Ophthalmol. 2008;2:837-48. https://doi.org/10.2147/OPTH.S1629

38. Loges L, González B, Farias-da-Rosa N. Seroprevalence and associated factors to Toxoplasma gondii infection in blood donors in Southern Brazil. Rev Panam Infectol. 2012;14:27-31.

39. La Opinión. Temperatura en Cúcuta aumentó $2,2^{\circ} \mathrm{C}$. 2016. Fecha de consulta: 21 de diciembre de 2017. Disponible en: https://www.laopinion.com.co/cucuta/temperatura-encucuta-aumento-22-degc-ideam-106636\#OP

40. WHO Expert Group. Expert Consensus Statement on achieving self-suffciency in safe blood and blood products, based on voluntary non-remunerated blood donation (VNRBD). Vox Sanguinis. 2012;103:337-42. https://doi.org/10.1111/j.1423-0410.2012.01630.x

41. Morales J, Fuentes-Rivera J, Delgado-Silva C, Matta-Solís H. Marcadores de infección para hepatitis viral en donantes de sangre de un hospital nacional de Lima metropolitana. Rev Peru Med Exp Salud Pública. 2017;34:466-71. https://doi.org/10.17843/rpmesp.2017.343.2503

42. Mahmood S, AL-Qadhi B, Zghair K. Prevalence of toxoplasmosis of male blood donors in Baghdad. Iraqui Journal of Science. 2013;54:832-41.

43. Alvarado-Esquivel C, Sánchez-Anguiano LF, Hernández-Tinoco J, Ramos-Nevarez A, Estrada-Martínez S, Cerrillo-Soto SM, et al. Association between Toxoplasma gondii infection and history of blood transfusion: A case-control seroprevalence study. J Int Med Res. 2018;46:1626-33. https://doi.org/10.1177/0300060518757928

44. Bastien P. Molecular diagnosis of toxoplasmosis. Trans R Soc Trop Med Hyg. 2002;96:S205-S15. https://doi.org/10.1016/S0035-9203(02)90078-7

45. Ivovic V, Vujanic M, Zivkovic T, Klun I, Djurkovic-Djakovic O. Molecular detection genotyping of Toxoplasma gondii from clinical samples. Intechopen. 2012 Fecha de consulta: 9 de septiembre de 2017. Disponible en: https://www.intechopen.com/books/toxoplasmosisrecent-advances/molecular-detection-and-genotyping-of-toxoplasma-gondii-from- and clinical-samples

46. Silveira C, Vallochi AL, da Silva UR, Muccioli C, Holland GN, Nussenblatt RB, et al. Toxoplasma gondii in the peripheral blood of patients with acute and chronic toxoplasmosis. J Ophthalmology. 2010;95:396-400. https://doi.org/10.1136/bjo.2008.148205

47. Bianchi M, Vaglio S, Pupella S, Marano G, Facco G, Liumbruno GM, et al. Leucoreduction of blood components: An effective way to increase blood safety? Blood Transfus. 2016;14:21427. https://doi.org/10.2450/2015.0154-15 